\title{
Prevalence of Stunting among Children Aged 6-23 Months in Kemba Woreda, Southern Ethiopia: A Community Based Cross-Sectional Study
}

\author{
Eskezyiaw Agedew ${ }^{1}$ and Tefera Chane ${ }^{2}$ \\ ${ }^{1}$ Department of Public Health, Arba Minch University, Southern Ethiopia, Ethiopia \\ ${ }^{2}$ Department of Public Health, Wolaita Sodo University, 251138 Southern Ethiopia, Ethiopia \\ Correspondence should be addressed to Eskezyiaw Agedew; esklagid@gmail.com
}

Received 27 March 2015; Revised 19 April 2015; Accepted 7 May 2015

Academic Editor: Ronald J. Prineas

Copyright (c) 2015 E. Agedew and T. Chane. This is an open access article distributed under the Creative Commons Attribution License, which permits unrestricted use, distribution, and reproduction in any medium, provided the original work is properly cited.

\begin{abstract}
Background. Stunting is a public health problem in developing countries. Stunting (HAZ $<-2 Z$-score) is a major cause of disability preventing children who survive from reaching their full developmental potential. Objective. To assess stunting and associated factors among children aged 6-23 months in Southern Ethiopia. Methods. Community based cross-sectional study was carried out among 562 mothers who have children from 6 to 23 months in 2014/15 in Kemba district. Multivariate analyses were applied to identify predictor variables and control effect of confounding. Results. The study revealed that out of 562 children, $18.7 \%$ ( $95 \%$ CI (15.6-22.1)) of children were stunted. In multiple logistic regressions, boys [AOR: 2.50; 95\% CI (1.60-4.01)], older mothers [AOR: 2.60; 95\% CI (1.07-6.35)], mothers who have no formal education [AOR: 2.76; 95\% CI (1.63-4.69)], mothers who work as daily workers [AOR: 3.06; 95\% CI (1.03-9.12)] and have private work activity [AOR: 2.39; 95\% CI (1.61-3.53)], mothers who have no postnatal follow-up [AOR: 1.64; 95\% CI (1.05-2.55)], and maternal illness encountered after delivery [AOR: 1.56; 95\% CI (1.052.32)] were identified as significant independent predictors of childhood stunting. Conclusion and Recommendation. A significant number of children had chronic undernutrition in critical periods. An organized effort should be made at all levels to solve the problems of chronic undernutrition (stunting) in children.
\end{abstract}

\section{Introduction}

Poor linear growth, or stunting (low length- or height-forage), in young children is the result of multiple circumstances and determinants, including antenatal, intrauterine, and postnatal malnutrition, more commonly due to inadequate or inappropriate nutrition and the impact of infectious disease. Childhood stunting continues to be a public health issue in many African countries [1,2].

Stunting in early life is associated with adverse functional consequences and growth failure during infancy and early childhood is often irreversible, leading to short stature during adolescence and adulthood. Stunting is associated with an elevated risk of child mortality, increased susceptibility to infection, and poor cognitive and psychomotor development. The long-term consequences of stunting include deficits in school achievement, reduced work capacity, and adverse pregnancy outcomes. Worldwide, stunting affects nearly onethird of children under 5 years of age, with the prevalence being higher in low-resource countries in sub-Saharan Africa and South Asia [3-5]. Stunting is a multifactorial phenomenon with a high prevalence in developing countries [6]. Globally, it is estimated that undernutrition is responsible, directly or indirectly, for at least $35 \%$ of deaths in children less than five years of age. Stunting (deficit in height/length-forage of at least $-2 Z$-score) affects close to 195 million children under five years of age in the developing world [7].

Appropriate weaning and complementary feeding behaviors, nutritional interventions, and disease control and treatment programs are strategies to prevent stunting. However, their effectiveness also depends on counteracting the environmental and socioeconomic circumstances that allow infection and suboptimal nutrition to persist $[1,6]$. 
The period from birth to two years of age is particularly important because of the rapid growth and brain development that occurs during this time. The period is often marked by growth faltering, micronutrient deficiencies, and common childhood illnesses [8].

Infant-feeding practices constitute a major component of child caring practices apart from sociocultural, economic, and demographic factors. Somehow, these practices constitute one of the most neglected determinants of young child malnutrition in spite of their important role in growth pattern of children [9].

Data exists in Ethiopia showing the problem of malnutrition beginning early in life, primarily during the first 12 months, when growth faltering takes hold due to suboptimal infant feeding practices. Stunted infants grow to be stunted children and stunted adults [10]. At national level, $44 \%$ of children under age of five are stunted and $21 \%$ of children are severely stunted [11]. In order to effectively accomplish the goals of Accelerated Stunting Reduction, identifying the potential determinants of chronic undernutrition is a vital step to reduce the burden of stunting. Therefore, the aim of this study was to have detailed and concrete data that fill these gaps and would add a value that directs policy makers to draw appropriate intervention measures to improve and flourish the health of future generation.

\section{Methods and Materials}

2.1. Study Setting and Source Population. This community based cross-sectional study was carried out in December 727/2014 on 562 mothers who have young child from 6 months to 2 years of age in Kemba Woreda located in Southern parts of Ethiopia. The Southern Nations Nationalities and People's Regional State (SNNPRS) consists of 13 zones and 104 woreda. The region has an estimated 15,042,531 (20.4\% of the national estimate) people. Close to $90 \%$ of the population are estimated to be rural inhabitants, while $1,545,710$ or $10.3 \%$ are urban. Kemba Woreda is one of the administrative woreda in Gamo Gofa Zone, South Ethiopia, $100 \mathrm{~km}$ away from zonal town Arba Minch. From the total population around 44,000 are women in reproductive age group. The health institution distribution in the woreda is 39 health posts and 9 health centers providing health services including maternal and child health care.

2.2. Inclusion and Exclusion Criteria. Mothers/care givers who have young children from 6 months to 23 months old who live in the selected Keble for at least 6 months were included in the study and those who had mental illnesses interfering with the interview were not considered in study.

2.3. Sample Size Determination and Sampling Methods. The sample size was determined by using single population proportion formula by the following assumption for prevalence of stunting (chronic malnutrition) as $44 \%$ in SNNPR,
Southern Ethiopia [12], desired precision $(d)$ as 5\% and $95 \%$ as confidence interval:

$$
N=\frac{((z / 2) \alpha)^{2} p(1-p)}{d^{2}}
$$

The final sample size was calculated by taking 1.5 as design effect which is 567 .

2.4. Sampling Methods. Interviewed mothers were selected from eight kebeles which were selected by using lottery method from all kebeles. Then the number of study participants was allocated for each kebele based on proportional to population size allocation methods by using community based demographic and health related information registration prepared by Health Extension workers as the sampling frame. Rapid censuses were conducted first to identify the target household. Finally infant-mother pairs were selected from each kebele by using simple random sampling methods after giving code for each household which has young child from six months to 24 months (Figure 1).

2.5. Data Collection Methods, Measurement, and Quality Control. Data was collected from mothers/care givers who have one child in age 6 months to 23 months from each household by direct interviewing. Pretested structured questionnaire adapted from different literature was used to collect sociodemographic and other variables. The questionnaire were arranged and grouped according to the issue addressed.

First the questionnaire was prepared in English and translated to Amharic and pretested on 5\% of mothers before actual data collection outside the selected kebeles; correction and modification was done based on the gap identified during interview. Six Grade 12 completed students were recruited as data collectors and supervised by 3 nurses. Three-day training was given on the aim of the research, content of the questionnaire, and how to conduct interview for data collectors and supervisor to increase their performance in field activities. The collected data were checked every day by supervisors and principal investigator for its completeness and consistency.

Anthropometric measurements such as weight and height were measured using standard technique and calibrated equipment. The weight of each child was taken by using digital scale wearing light cloth, checking the calibration using $2 \mathrm{~kg}$ rod during each instant of weight measuring, and the measurement was approximated to the nearest $10 \mathrm{~g}$. Children were not in fasting condition and each subject was weighted twice and the average weight was taken. Length was measured in recumbent position using sliding board by two data collectors and taken to the nearest $1 \mathrm{~mm}[2,13,14]$. The data collectors were trained efficiently on how to take the anthropometric measurements.

2.6. Data Analysis and Management. Data was coded and entered into Epi-Info version 3.5.1 and exported to SPSS version 20 for analysis. Exploratory data analysis was done to check missing values, potential outliers, and the normality distribution for those continuous variables. The presence of 


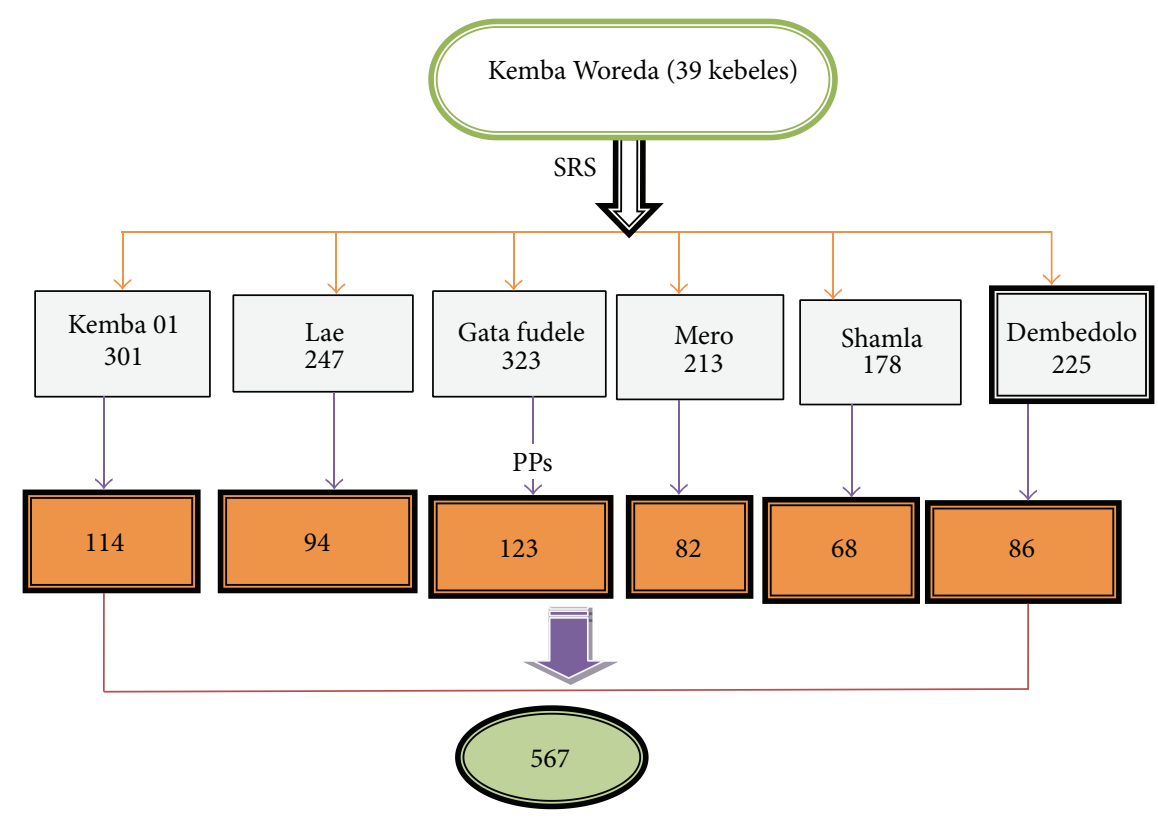

FIGURE 1: Schematic presentation of sampling procedure in Kemba Woreda, Southern Ethiopia, 2014/15.

multicollinearity also was checked and effort was made to incorporate different models to cross check. Anthropometric index (HAZ) was analyzed by using WHO Anthro software version 3.2.2 and categorized as stunted if $\mathrm{HAZ}<-2 \mathrm{Z}$ score and as normal if $\mathrm{HAZ}>-2 Z$-score; stunting is defined as $\mathrm{HAZ}<-2 \mathrm{SD}$ [13]. Extreme outlier of $<-6 Z$-score of HFA was omitted from the analysis. Descriptive frequencies were calculated to describe the study population in relation to relevant variables. Bivariate logistic regression analysis was calculated to assess the crude association between dependent and independent variables. Finally variables which show association in bivariate logistic regression analysis and have $P$ value less than 0.25 (not to miss some of important variables that are not significant in the bivariate analysis) were entered into multivariate logistic regression model, to identify significant independent predictors of stunting and to control the possible effect of confounding. Variables with $P$ value less than 0.05 were identified as significant predictors of stunting.

2.7. Ethical Consideration. Ethical clearance was obtained from Research Ethics Committee (REC) of Addis Continental Institute of Public Health. Permission letter was obtained from Kemba Woreda Health Office. Verbal informed consent from each study participant was obtained after clear explanation about the purpose of the study. All the study participants were reassured that only anonymous data were taken. They were given the chance to ask anything about the study and made free to refuse or stop the interview at any moment they want if that was their choice.

\section{Result}

3.1. Sociodemographic Characteristics of the Mothers and Young Child. A total of 562 women having young child aged 6 months to 23 months were interviewed in the study from 567 sampled mothers with $99.11 \%$ response rate. The mean age of children were 13.82 months with \pm 5.85 standard deviation and $53 \%$ of them were found in age range from 6 months to 1 years and $273(48.6 \%)$ were boys and 289 (51.4\%) were girls with sex ratio of 0.94 . Almost half of the mothers, 271 (48.2\%), were in age range 25-29 years. About one-third of respondents $(30.8 \%)$ had no formal education and $46 \%$ of them were farmers and daily workers in their occupational status. About two-thirds of the respondent mothers 348 (61.9\%) were Protestant followers and the rest were Orthodox and Muslims (Table 1).

3.2. Prevalence of Chronic Undernutrition (Stunting). From 562 interviewed mothers-child pair 18.7\%, 95\% CI (15.6$22.1)$, out of all children, $25.8 \%$; 95\% CI (20.8-31.4) boys and 12.5\%; 95\% CI (8.5-16.0) girls had chronic undernutrition. The level of moderate stunting was $10.4 \%$; 95\% CI (7.9-12.9). Among all boys, 14.4\%; 95\% CI (10.2-18.6) and among all girls, 6.8\%; 95\% CI (3.9-9.7) boys and girls had moderate chronic undernutrition respectively. The prevalence of severe stunting (HAZ < -3 Z-score) was 8.4\%, 95\% CI (6.1-10.7). In the overall scenario, boys were more affected than girls. There were higher numbers of stunted boys than stunted girls (Figure 2).

3.3. Factors Associated with Chronic Undernutrition (Stunting). Variables like sex of child [AOR: 2.50; 95\% CI (1.60$4.01)$ ], age of mothers those in age group $\geq 30$ years [AOR: 2.60; 95\% CI (1.07-6.35)], education level those who have no formal education [AOR: 2.76; 95\% CI (1.63-4.69)], occupational of mothers those who work as daily workers [AOR: 3.06; 95\% CI (1.03-9.12)] and Private work activity (merchant, farmers) [AOR: 2.39; 95\% CI (1.61-3.53)], mothers who have 
TABLE 1: Sociodemographic characteristics of mothers, who had infant aged from 6-23 months, who live in Kemba Woreda, 2014/15.

\begin{tabular}{|c|c|c|}
\hline Variables & Frequency $(n=562)$ & Percent $(\%)$ \\
\hline \multicolumn{3}{|l|}{ Age of child } \\
\hline $6-8$ months & 125 & 22.2 \\
\hline 9-12 months & 172 & 30.6 \\
\hline 13-17 months & 119 & 21.2 \\
\hline $18-23$ months & 146 & 26.0 \\
\hline \multicolumn{3}{|l|}{ Sex of child } \\
\hline Male & 273 & 48.6 \\
\hline Female & 289 & 51.4 \\
\hline \multicolumn{3}{|l|}{ Residence of mother } \\
\hline Rural & 205 & 36.5 \\
\hline Urban & 357 & 63.5 \\
\hline \multicolumn{3}{|l|}{ Age of mother } \\
\hline $15-19$ & 97 & 17.3 \\
\hline $20-24$ & 165 & 29.4 \\
\hline $25-29$ & 256 & 45.6 \\
\hline$\geq 30$ & 44 & 7.7 \\
\hline \multicolumn{3}{|l|}{ Religion status } \\
\hline Orthodox & 197 & 35.1 \\
\hline Protestant & 348 & 61.9 \\
\hline Muslim & 17 & 3.0 \\
\hline \multicolumn{3}{|l|}{ Education } \\
\hline No education & 173 & 30.8 \\
\hline Primary education & 202 & 35.9 \\
\hline Secondary and above & 187 & 33.3 \\
\hline \multicolumn{3}{|l|}{ Occupational status } \\
\hline Daily laborer & 20 & 3.6 \\
\hline Private (merchant, farmers) & 259 & 46.1 \\
\hline Government worker & 27 & 4.8 \\
\hline Housewife & 256 & 45.6 \\
\hline \multicolumn{3}{|l|}{ Ethnicity } \\
\hline Gamo and Gofa & 491 & 87.4 \\
\hline Wolaita & 58 & 10.3 \\
\hline Amhara & 11 & 2.0 \\
\hline Others & 2 & 0.4 \\
\hline
\end{tabular}

no postnatal follow up for their child in Health service [AOR: 1.64; 95\% CI (1.05-2.55)], and maternal illness encountered after delivery [AOR: 1.56; 95\% CI (1.05-2.32)] were significantly associated with chronic undernutrition. However, variables such as place of residence, place of delivery, and ANC followup did not show statistical association with chronic undernutrition (Table 2).

\section{Discussion}

The result of this study showed that the prevalence of stunting (HAZ < -2 SD) was 18.7\% 95\% CI (15.6-22.1). Boys were more likely to be stunted than girls (25.8\% versus $12.5 \%)$. The prevalence of stunting in this setting was much lower than findings from different parts of Ethiopia (Bule Hora (47.6\%), Jimma arjo (41.4\%)) [14] and even lower than the

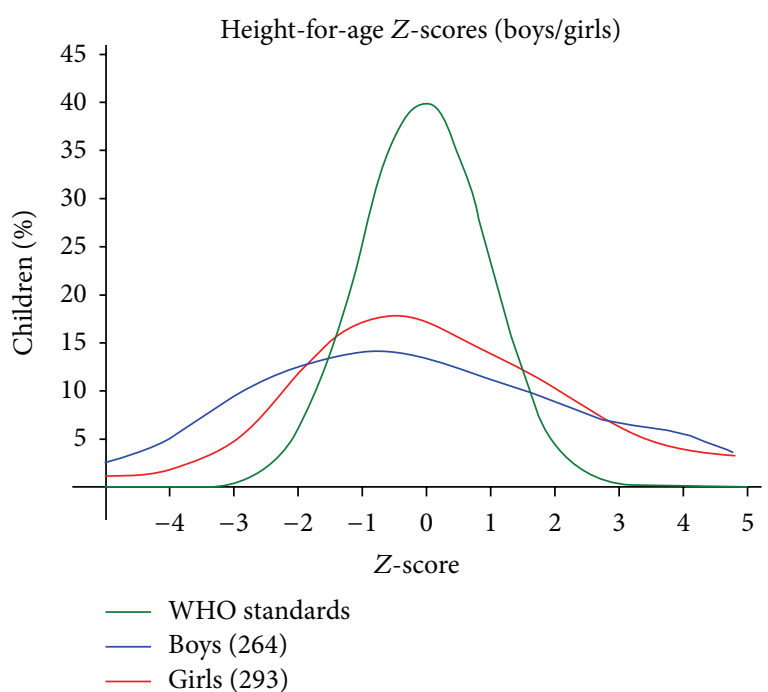

FIGURE 2: Distribution of chronic undernutrition/stunting by sex among children 6-23 months of age residing in Kemba Woreda, Southern Ethiopia, 2014/15.

regional stunting levels of Ethiopian demographic and health surveillance report [11], Eastern Kenya (33.3\%) [15], and this finding was consistent with finding from Johannesburg (18\%) [16]. In contrast to the above findings, the magnitude of stunting in the our study area was higher than report from Latin America and Caribbean countries (11\%) [17]. The reason why the finding in our setting is lower than the others may be due to the narrowing of age of children in the study making the magnitude of stunting declined as compared to studies having wide target children $<5$ years of age. The reason goes in line with findings from Eastern Kenya showing that stunting is more prevalent in children $>2$ years [15].

In this study, child sex, maternal age, maternal educational level and occupational status, and postnatal followup were statistically significant with chronic undernutrition. Having no formal education of mothers and older mothers (>31 years) were negatively associated with the nutritional status of children. Similarly the findings are supported with findings from Johannesburg, Tanzania, and Kenya [15, 16, 18]. Having maternal illness and not attending postnatal care were also independent predictors of stunting.

\section{Strength and Weakness of the Study}

This study is community based showing real nutritional condition of children 6-23 months of age. Thus it has strong generalization power because other studies were conducted with relatively small sample size and were institutional based. Recall bias may be introduced even if it was minimized by probing mothers to report by association with different life events may not remember events occurred in the past, and possibility of interviewer bias and misreporting of events were the potential limitation. Another limitation of the study was failing to incorporate wealth index, dietary diversity, and household food security. 
TABLE 2: Factors associated with stunting among mothers who have 6-23 months of young child in Kemba Woreda in 2014/15.

\begin{tabular}{|c|c|c|c|c|c|}
\hline \multirow{2}{*}{ Explanatory variable } & \multicolumn{2}{|c|}{ Chronic nutritional status } & \multirow{2}{*}{ Crude OR $(95 \%$ CI $)$} & \multirow{2}{*}{ Adjusted OR (95\% CI) } & \multirow{2}{*}{$P$ value } \\
\hline & Normal (\%) & Stunted (\%) & & & \\
\hline \multicolumn{6}{|l|}{ Residence } \\
\hline Rural & $159(77.6)$ & $46(22.4)$ & $1.50(1.04-3.33)$ & $1.34(0.82-2.19)$ & 0.24 \\
\hline Urban & $298(83.5)$ & $59(16.5)$ & 1 & 1 & \\
\hline \multicolumn{6}{|l|}{ Sex of child } \\
\hline Male & $204(74.2)$ & $69(25.8)$ & $2.43(1.56-3.80)$ & $2.50(1.60-4.01)$ & 0.001 \\
\hline Female & $253(87.5)$ & $36(12.5)$ & 1 & & \\
\hline \multicolumn{6}{|l|}{ Age of mother } \\
\hline$\leq 19$ & $74(76.3)$ & $23(23.7)$ & 1 & 1 & \\
\hline $20-24$ & $144(87.3)$ & $21(12.7)$ & $1.03(0.60-1.74)$ & $1.15(0.647-2.08)$ & 0.620 \\
\hline $25-30$ & $203(79.3)$ & $53(20.7)$ & $1.20(0.74-1.95)$ & $0.97(0.54-1.75)$ & 0.924 \\
\hline$\geq 31$ & $36(81.8)$ & $8(18.2)$ & $1.96(0.94-4.09)$ & ${ }^{*} 2.60(1.07-6.35)$ & 0.035 \\
\hline \multicolumn{6}{|l|}{ Maternal education level } \\
\hline No formal education & $102(75.6)$ & $33(24.4)$ & $3.08(1.98-4.79)$ & $* 2.76(1.63-4.69)$ & 0.001 \\
\hline Primary education & $199(80.9)$ & $47(19.1)$ & $1.72(1.15-2.57)$ & $1.42(0.89-2.25)$ & \\
\hline Secondary and above & $156(86.2)$ & $25(13.8)$ & 1 & 1 & \\
\hline \multicolumn{6}{|l|}{ Occupational status } \\
\hline Daily laborer & $16(72.7)$ & $6(17.3)$ & $3.55(1.40-9.09)$ & *3.06 (1.03-9.12) & 0.045 \\
\hline Private (merchant, farmers) & $216(80.9)$ & $51(19.1)$ & $0.41(0.28-0.59)$ & ${ }^{*} 2.39(1.61-3.53)$ & 0.001 \\
\hline Government worker & $30(88.2)$ & $4(11.8)$ & $0.34(0.12-0.96)$ & $0.44(0.16-1.18)$ & 0.103 \\
\hline Housewife & $195(81.6)$ & $44(18.4)$ & 1 & 1 & \\
\hline \multicolumn{6}{|l|}{ Media exposure } \\
\hline Yes & $251(83.7)$ & $49(16.3)$ & 1 & & \\
\hline No & $206(78.6)$ & $56(21.4)$ & $1.91(1.35-2.69)$ & $0.86(0.53-1.39)$ & 0.54 \\
\hline \multicolumn{6}{|l|}{ Place of delivery } \\
\hline Home & $153(78.9)$ & $41(21.1)$ & $1.25(0.87-1.78)$ & $1.41(0.89-2.24)$ & 0.14 \\
\hline Health facility & $304(82.6)$ & $64(17.4)$ & 1 & 1 & \\
\hline \multicolumn{6}{|l|}{ ANC followup } \\
\hline Yes & $404(81.3)$ & 93 (18.7) & 1 & 1 & \\
\hline No & $53(81.5)$ & $12(18.5)$ & $1.66(0.95-2.89)$ & $0.82(0.44-1.57)$ & 0.55 \\
\hline \multicolumn{6}{|l|}{ PNC followup } \\
\hline Yes & $132(84.1)$ & $25(15.9)$ & 1 & 1 & \\
\hline No & $325(80.2)$ & $80(19.8)$ & $1.80(1.48-3.2)$ & ${ }^{*} 1.64(1.05-2.55)$ & 0.029 \\
\hline \multicolumn{6}{|l|}{ Maternal illness } \\
\hline Yes & $19(79.2)$ & $5(20.8)$ & $1.40(0.99-1.96)$ & ${ }^{*} 1.56(1.05-2.32)$ & 0.027 \\
\hline No & $437(81.4)$ & $100(18.6)$ & 1 & 1 & \\
\hline
\end{tabular}

${ }^{*}$ Significant factors.

\section{Conclusion and Recommendation}

A significant number of young children were affected by chronic malnutrition. Stunting was significantly associated with child sex, maternal illiteracy, mothers who work as daily workers and have private work, and those having no postnatal followup and maternal illness encountered after delivery. An organized effort should be made at all levels to improve maternal education, postnatal care practice, and maternal health status to solve the problems of chronic undernutrition (stunting) in children, especially in such critical periods, to avoid its effect on future development of young children. Appropriate and early intervention should be designed at health facility and community level for mothers to have postnatal followup since it is an opportunity for health professional to give nutrition education for mothers. Further research should be conducted to investigate specific nutrient deficiency status in body serum by using laboratory methods.
Abbreviations
AOR: Adjusted odds ratio
SAM: Severe acute malnutrition
MUAC: Mid-upper-arm circumference
CI: Confidence interval
SD: Standard deviation
TFU: Therapeutic feeding unit. 


\section{Conflict of Interests}

The authors declare that they have no conflict of interests.

\section{Authors' Contribution}

Eskezyiaw Agedew initiated the research, wrote the research proposal, conducted the research, did data entry and analysis, and wrote the paper. Tefera Chane contributed in the designing of methodology and writing of proposal.

\section{Acknowledgments}

The authors would like to thank Arba Minch University for funding their research work. Their deepest gratitude goes to data collectors, kebeles leaders, and Kemba Woreda Health Center Manager for his cooperation starting from the beginning till the end of data collection time.

\section{References}

[1] B. A. Willey, N. Cameron, S. A. Norris, J. M. Pettifor, and P. L. Griffiths, "Socio-economic predictors of stunting in preschool children-a population-based study from Johannesburg and Soweto," South African Medical Journal, vol. 99, no. 6, pp. 450456, 2009.

[2] M. de Onis, M. Blössner, and E. Borghi, "Prevalence and trends of stunting among pre-school children, 1990-2020," Public Health Nutrition, vol. 15, no. 1, pp. 142-148, 2012.

[3] J. H. Rah, N. Akhter, R. D. Semba et al., "Low dietary diversity is a predictor of child stunting in rural Bangladesh," European Journal of Clinical Nutrition, vol. 64, no. 12, pp. 1393-1398, 2010.

[4] UNC's Fund, The State of the World's Children 2009, UNICEF, 2008.

[5] C. G. Victora, L. Adair, C. Fall et al., "Maternal and child undernutrition: consequences for adult health and human capital," The Lancet, vol. 371, no. 9609, pp. 340-357, 2008.

[6] M. T. Ruel and P. Menon, "Child feeding practices are associated with child nutritional status in Latin America: innovative uses of the Demographic and Health Surveys," Journal of Nutrition, vol. 132, no. 6, pp. 1180-1187, 2002.

[7] World Health Organization, Global Data Bank on Infant and Young Child Feeding, World Health Statistics, World Health Organization, Geneva, Switzerland, 2010.

[8] T. Wolde, E. Adeba, and A. Sufa, "Prevalence of chronic malnutrition (stunting) and determinant factors among children aged 0-23 months in Western Ethiopia: a cross-sectional study," Journal of Nutritional Disorders \& Therapy, vol. 4, article 148, 2014.

[9] D. Kumar, N. K. Goel, P. C. Mittal, and P. Misra, "Influence of infant-feeding practices on nutritional status of under-five children," Indian Journal of Pediatrics, vol. 73, no. 5, pp. 417-421, 2006.

[10] E. W. Kimani-Murage, N. J. Madise, J.-C. Fotso et al., "Patterns and determinants of breastfeeding and complementary feeding practices in urban informal settlements, Nairobi Kenya," BMC Public Health, vol. 11, article 396, 2011.

[11] Central Statistical Agency and ICF Macro, Ethiopia Demographic and Health Survey 2011, Central Statistical Agency, Addis Ababa, Ethiopia; ICF Macro, Calverton, Md, USA, 2012.
[12] Central Statistical Agency and ORC Macro, Ethiopia Demographic and Health Survey, Central Statistical Agency, Addis Ababa, Ethiopia; ORC Macro, Calverton, Md, USA, 2011.

[13] WHO, WHO Multicenter Growth Reference Study Group. WHO Child Growth Standards: Length/Height-for-Age, Weightfor-Age, Weight-for-Length, Weight-for-Height and Body Mass Index-for-Age: Methods and Development, World Health Organization, Geneva, Switzerland, 2006.

[14] M. Asfaw, M. Wondaferash, M. Taha, and L. Dube, "Prevalence of undernutrition and associated factors among children aged between six to fifty nine months in Bule Hora district, South Ethiopia," BMC Public Health, vol. 15, no. 1, p. 41, 2015.

[15] Z. N. Bukania, M. Mwangi, R. M. Karanja et al., "Food insecurity and not dietary diversity is a predictor of nutrition status in children within semiarid Agro-Ecological zones in Eastern Kenya," Journal of Nutrition and Metabolism, vol. 2014, Article ID 907153, 9 pages, 2014.

[16] B. A. Willey, N. Cameron, S. A. Norris, J. M. Pettifor, and P. L. Griffiths, "Socio-economic predictors of stunting in preschool children-a population-based study from Johannesburg and Soweto," South African Medical Journal, vol. 99, no. 6, pp. 450456, 2009.

[17] UNICEF, Improving Child Nutrition: The Achievable Imperative for Global Progress, UNICEF, 2013.

[18] C. M. Mcdonald, R. Kupka, K. P. Manji et al., "Predictors of stunting, wasting and underweight among Tanzanian children born to HIV-infected women," European Journal of Clinical Nutrition, vol. 66, no. 11, pp. 1265-1276, 2012. 


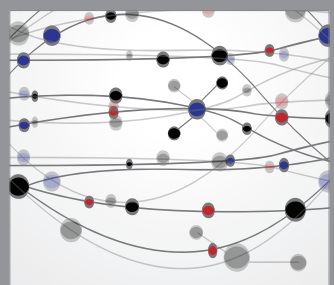

The Scientific World Journal
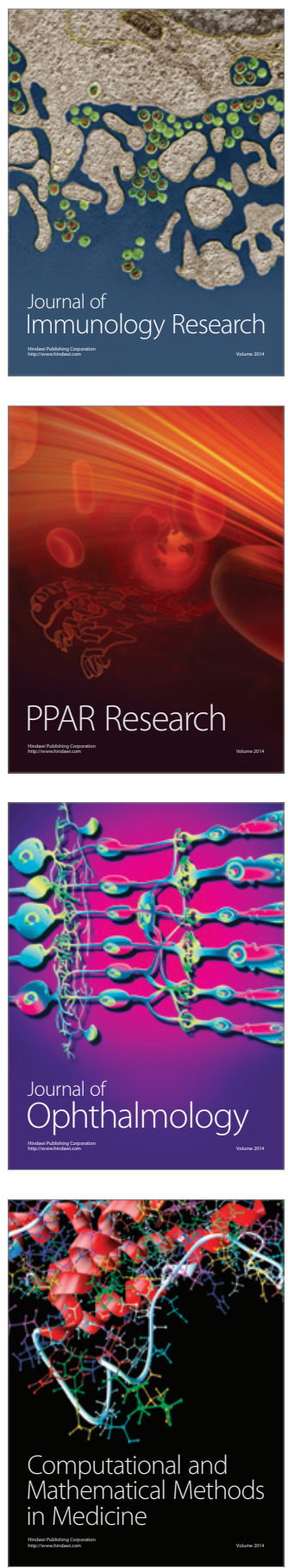

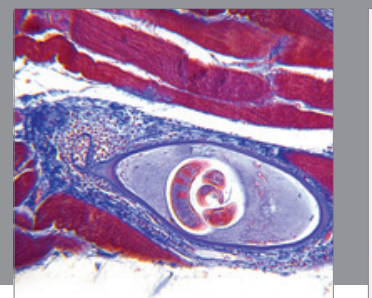

Gastroenterology

Research and Practice
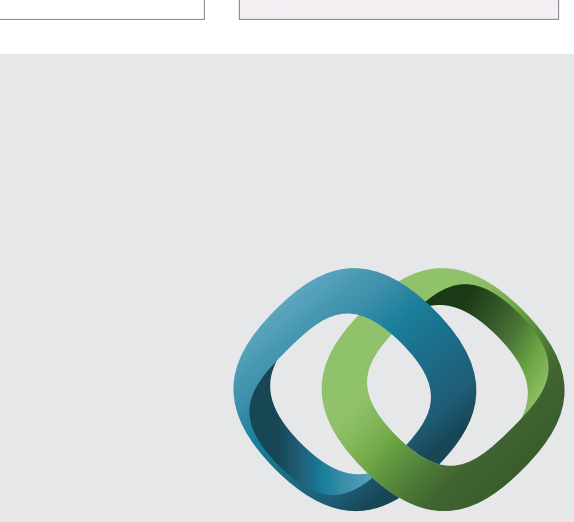

\section{Hindawi}

Submit your manuscripts at

http://www.hindawi.com
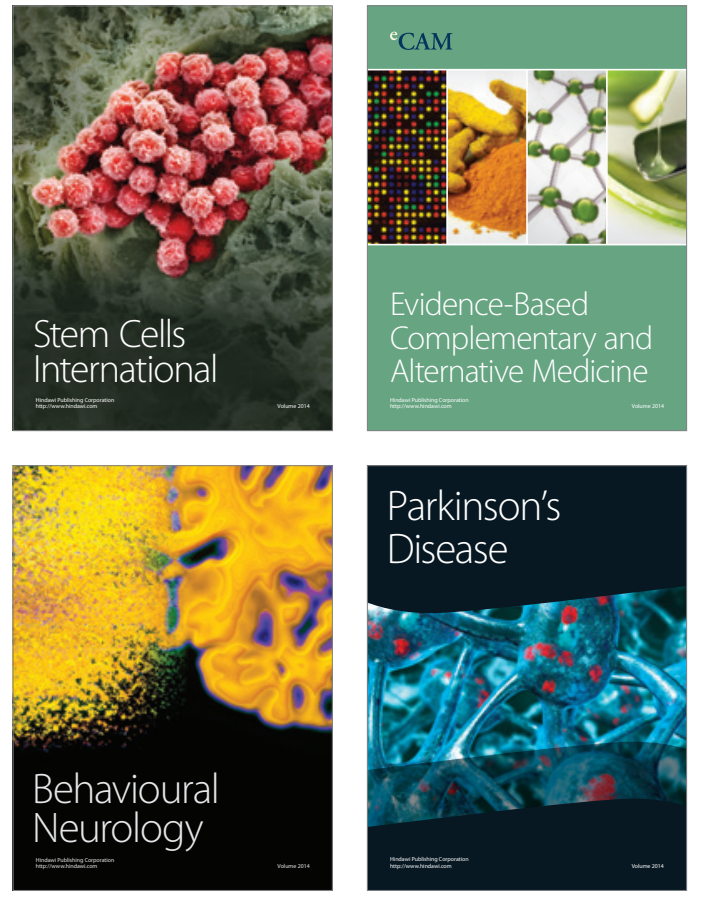
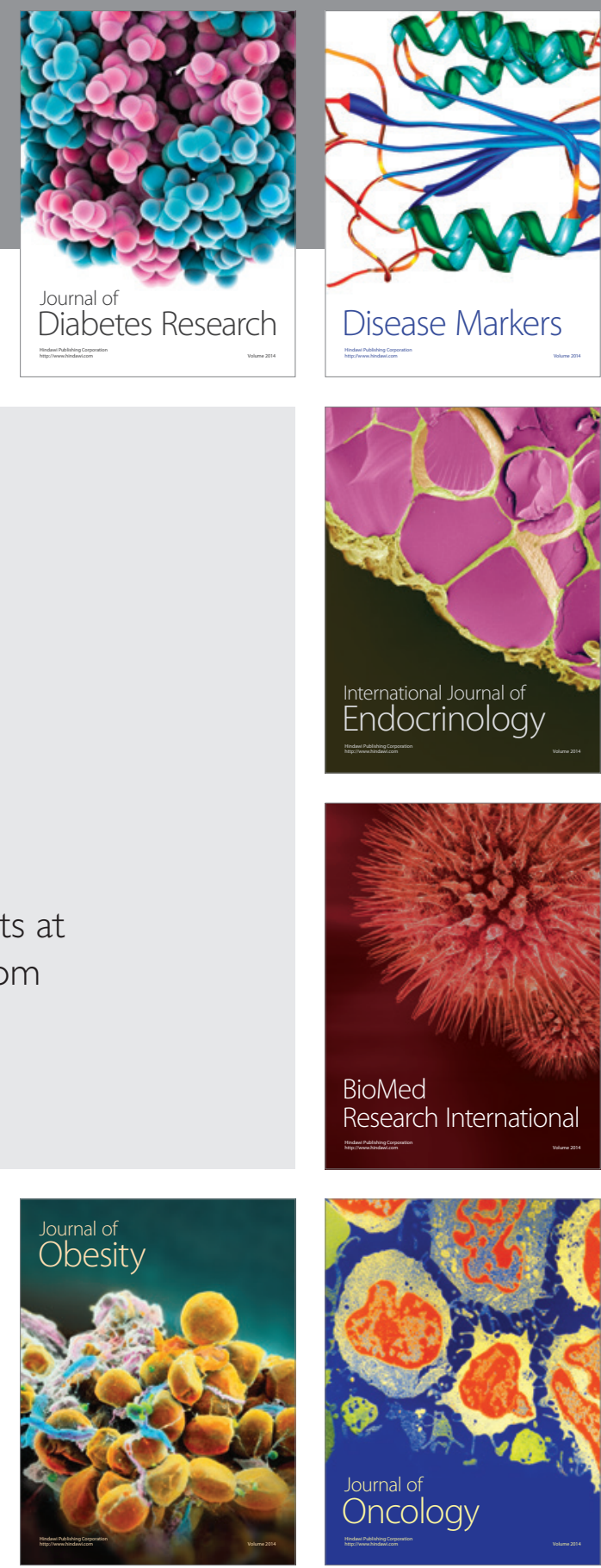

Disease Markers
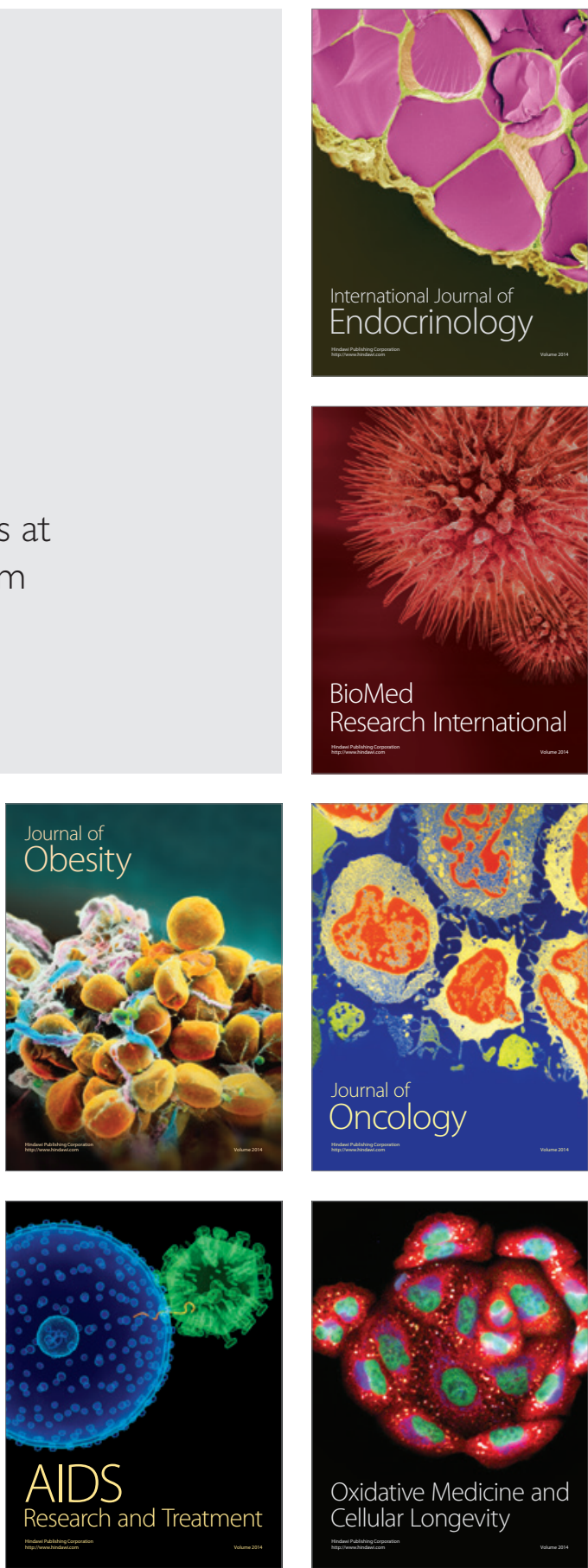